3. Enable PYP Saudi EFL learners to produce wellstructured sentences.

4. Urge EFL teachers to implement effective methods of teaching writing skills Saudi EFL classroom.

5. Find out possible teaching tips to get rid of PYP Saudi EFL learners' learning difficulties.

6. Develop teaching practice to decrease awkward sentences of learners' paragraph writing.

\section{Questions of the Study}

The study attempts to answer the following questions:

1. In What way can grammatical errors affect PYP Saudi EFL leaners' written discourse?

2. What are the correlations between erroneous sentences and PYP Saudi EFL learners' paragraph writing?

3. To what extent can effective EFL teaching methods improve PYP Saudi EFL learners' writing skills production?

\section{Methodology of the Study}

The researcher will adopt an eclectic method in which the experimental method is used as the main method and also the study includes the analytical and descriptive methods to be conducted. The tools will be used for data collection are the Pre-test and Posttest administered to (40) EFL Saudi learners (male part), teachers' questionnaire is delivered to (50) of the staff of English EFL teachers across different colleges with considerable experience of teaching English writing and grammar. The subjects of the study are male learners of PYP at the university level selected as (20) controlled group, and (20) experimental group so as to elicit their performance and perceptions of writing paragraph. The obtained data will be analyzed via SPSS computer software program.

\section{Literature Review}

\section{The Concept of Constructing Knowledge:}

Many people stress on prior knowledge of experience in learning. Vygotsky, (1978) pointed that a "learner's previous knowledge and experiences refers to learning as active processes of constructivism constructing meaning" (cited in Natalie 2009). Similarly, Schunk (2008) asserted that "constructivists' views are embedded within the social interaction of people and situations in knowledge acquisition"

\section{Mother Tongue:}

Dulay, Burt \& Krashen (1982) Stated that:
"The hypothesis of applied contrastive linguistics is that wherever there are similarities, learning can be facilitated and wherever there are contrasts, learning may be retarded or interfered with Facilitation and interference are spoken of as representing positive or negative transfer, respectively."

\section{Second Language Acquisition:}

The term "acquisition" is used to refer picking up a second language through exposure, whereas the term "learning" is used to refer the conscious study of a second language (Lado, (1964)).

\section{Importance of Structure to Convey Meaning:}

Dornyei, (2003) suggested that "it may be very difficult to eradicate LI parameter settings from the learners' linguistic output, even when the learner has conscious grammatical knowledge of the target form in the L2. Consideration must be given to the meanings that underlie the forms".

\section{Error Analysis Aspects:}

Brown (1980) stated that "error analysis is the study of Learners' errors which can be observed, analyzed and classified into something that reveals the system operating within the learners."

\section{Classification of Errors:}

Errors are categorized according to their features by Dulay, Burt and Krashen (1982) into six different categories:

Omission of grammatical morphemes, double marking of semantic features, use of irregular rules, use of wrong word forms, alternating use of two or more forms, and disordering.

\section{Error Description:}

According to Dulay, Burt and Krashen (1982) there are four types of errors: linguistic category taxonomy, surface strategy taxonomy, comparative taxonomy and communicative taxonomy.

\section{Difference between Errors and Mistakes:}

Brown (1980) stated that "mistakes refer to a performance error that is a failure to utilize a known language system correctly. In the second language literature performance, errors have been called "mistakes" while the term "errors" was reserved for the systematic deviation due to learners who are still developing knowledge of the random guess or a slip, which is failure to know system correctly. Mistakes are made by a native speaker and those mistakes make 
learners different. A native speaker frequently makes slip of false starts on conclusion of structure."

\section{English Academic Writing:}

According to Hornby, (1955), there are several definitions of writing, they are:

1. The activity or occupation of writing e.g. stories or article.

2. Books, Stories, Articles.

3. The literary style of such material.

4. Written works, e.g. books or essays.

According to Harris (1969) there are five general components to be recognized in writing process, they are:

1. Content: the substance of the writing; the idea expressed

2. Form: the organization of the content

3. Grammar: the employment of grammatical forms and syntactic patterns.

4. Style: the choice of structure and lexical items to give particular tone on flavor to the writing.

5. Mechanism: the use of graphic conventions of the language.

\section{English Grammar Review:}

Norrish, J. (1983: 83) said that "if the learners of English as a second language do not understand the concept of grammatical structure, they cannot advance their English at the high level".

\section{Perspective View of Teaching Writing:}

\section{Process Writing}

Brown, (1994) stated that:

A. Process writing necessitates the creation of classroom tasks to allow learners make choices of content and form themselves. It also includes the creation of an interactive framework for writing.

B. Writing as a process implies three participant roles:
I. writer
$\longrightarrow$ the learner.
II. reader
$\longrightarrow$ the audience.
III. teacher
the corrector.

C. The learner's written text takes on its "final" shape as a result of the work route.

D. Learners should know they are not writing for the teacher since he is a peculiar sort of reader who reads to identify errors, evaluate and mark.

E. Process writing simulates real-life writing for which a definite targeted audience is crucial.

F. In order for the process to be successful and function appropriately, learners should:
$>$ Have a purpose for writing.

$>$ Know their audience, i.e. whom they are writing to.

$>$ Know that the immediate aim is the route / path / way they use to get to the final product.

\section{Previous Studies:}

EL-Sayed (1982) investigated the frequent syntactic errors in compositions written by Saudi students. The errors were classified into verbs, verbal, articles, pronouns, nouns, adjectives, and prepositions. Verbs and verbal were found the major source of errors. His findings also supported the claim that mother tongue interference was the prime cause of errors. Similarly, Alamin (2012) investigated the syntactical and punctuation errors of Saudi student at Taif University. He classified those errors into syntactical errors and punctuation errors. He noted that a large portion of errors may go back to interference of the first language.

This part of the study reveals relevant literature in the field of ELT. It is unfolded Grammatical misconception, fragment and above all errors in writing. Literature has shown that it takes the willingness of the teachers to adapt collective strategies in their teaching to lessen such errors. However, for those teachers who are ready to improve their methods. literature reports that they face some challenges. This part introduce great deal of error analysis as well previous research findings.

\section{Research Design}

This study employs eclectic methods through which the experimental method is utilized as a main method beside the descriptive and the analytical methods to meet its aims. The idea behind using questionnaire is to elicit views from EFL teachers at Majmaah University - Preparatory Year Program PYP English Language Center ELC to yield the attitudes and perceptions of the those teachers. And also the test is employed to compile the required data from a purposive sample of (40) English language learners at PYP of medical college.

\section{Participants}

The participants of the study are EFL Saudi male learners at PYP who study several subjects, meanwhile English as a main subject at the University of Majmaah. The second type of participants are EFL/ESL teachers of English at Majmaah University, too. Thus, they are the participants of the subjects that 
the researcher intends to obtain his data for study from.

\section{Analysis, and Interpretation}

This study explores and analyzes the grammatical inaccuracy made by EFL Saudi male learners of medical college at PYP in terms of written discourse it explores this problem based on teachers' perspectives and learners' experience.

Data analysis is divided into two parts. The first part sheds a light on the first instrument through which the data were obtained for sake of this study (teachers' questionnaire). The second part covers the analysis of the second tool that used to collect data from the subjects (learners' test).

\section{Participants' Qualifications}

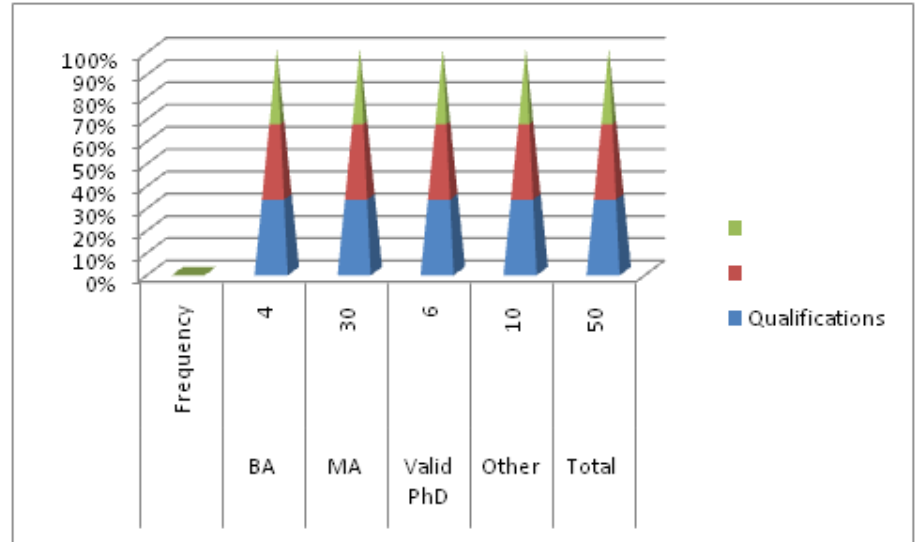

\section{Gender}

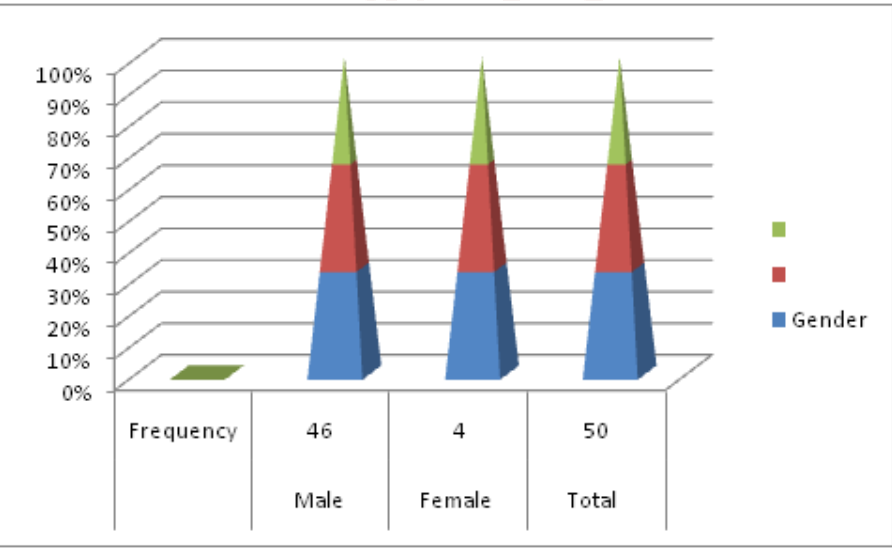

\section{Learners' Test Analysis}

This section will present the analysis of the pre-test and the post tests for both groups; the control group and the experiment group. The statistical techniques which will be used are:

1. Independent sample-tests

2. Paired samples t-tests
In order to carry out these analyses, there are some assumptions that have to be observed. These are:

1. Test of normality.

2. Test of homogeneity

The scores of the tests will be checked for statistically significant differences in order to provide evidence for the verification of hypotheses. The section below will present the tests of normality for the four sets of data. The test of homogeneity will be check later on with Levene's Test for Equality of Variances in the analysis of t-tests.

\section{Control Group pre-test :Tests of Normality}

\begin{tabular}{|c|c|c|c|c|c|c|}
\hline \multirow{2}{*}{} & \multicolumn{3}{|c|}{$\begin{array}{c}\text { Kolmogorov- } \\
\text { Smirnov }\end{array}$} & \multicolumn{3}{c|}{ Shapiro-Wilk } \\
\cline { 2 - 7 } & Statistic & df & Sig. & Statistic & df & Sig. \\
\hline Score & .186 & 20 & .069 & .925 & 20 & .126 \\
\hline
\end{tabular}

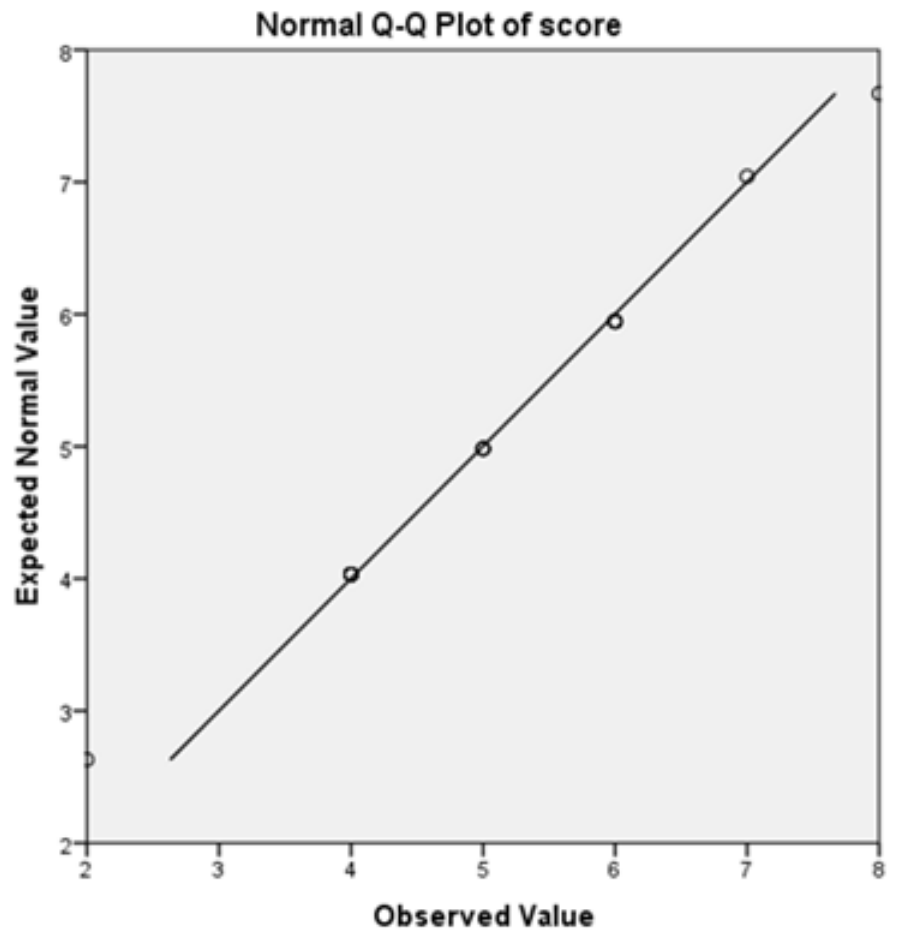

Experiment Group pre-test :Tests of Normality Tests of Normality

\begin{tabular}{|c|c|c|c|c|c|c|}
\hline \multirow{2}{*}{} & \multicolumn{2}{|c|}{$\begin{array}{c}\text { Kolmogorov- } \\
\text { Smirnov }\end{array}$} & \multicolumn{3}{c|}{ Shapiro-Wilk } \\
\cline { 2 - 7 } & Statistic & df & Sig. & Statistic & df & Sig. \\
\hline Score & .187 & 20 & .065 & .917 & 20 & .085 \\
\hline
\end{tabular}

a. Lilliefors Significance Correction 


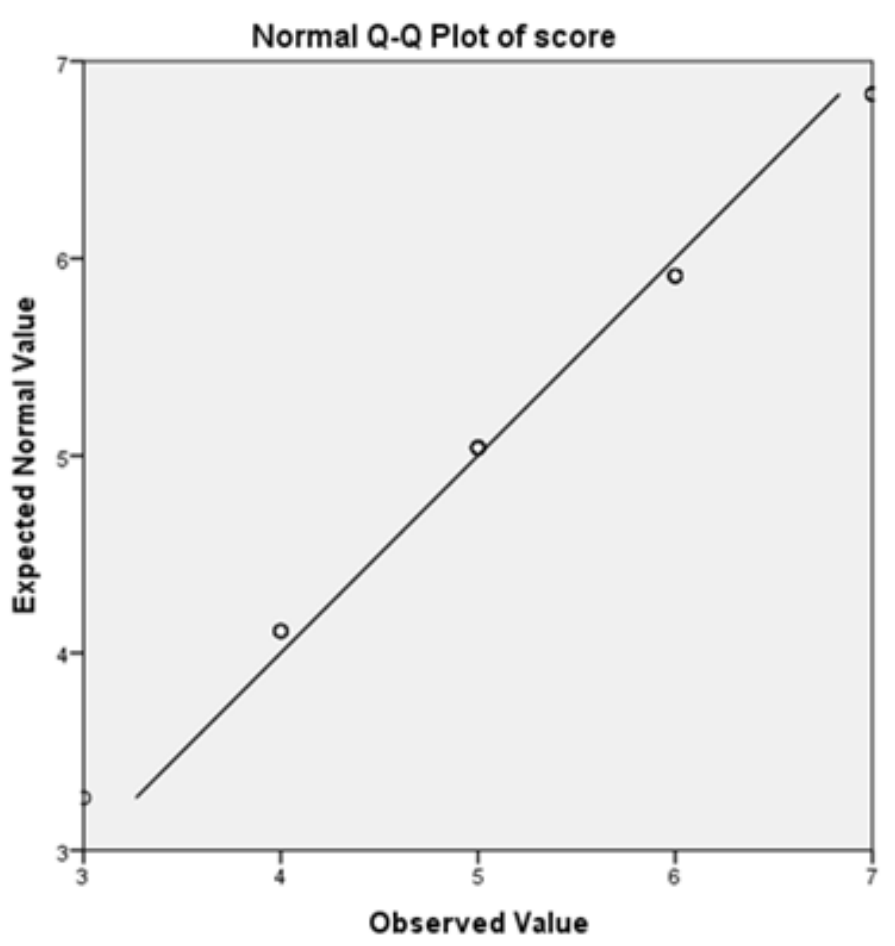

9. Conclusion

It can be concluded from the findings that EFL Saudi learners encounter difficulties when they have to write in English. The major causes of the errors are : the mother tongues interference in the second language learning process, weak teaching methods in EFL context, passive transfer of learners' first language and their incomplete knowledge of the target language. On the other hand, causes of errors such as learners' demotivation, reluctance and carelessness which cannot be overlooked. Analyzing learners' errors in written English and seeking for causes of those errors have been proven to be helpful to EFL and ESL learners' writing improvement. The present study, therefore, was conducted to find errors frequently found in English sentences written by Saudi EFL learners. Besides, developing EFL teaching methods so as to get better learning outcomes.

\section{Recommendations}

The researcher offers the following suggestions:

1. Mother tongue must be considered while teaching second language grammar.

2. Sentence structure of second language must be considered while teaching academic writing.

3. New trends, approaches and methods should be offered to equip teachers and learners with the practical knowledge at universities and colleges.

4. The production phase of all language skills must be written text.

5. Error analysis theories must be regarded in teaching language skills to guarantee the more effectiveness and efficiency of teaching

6. Training, workshops and/or seminars must be conducted with regard to systematic errors in EFL context.

7. Teachers should try as much to follow the newly invented methods and accustomed their learners with. 